WellBeing International

WBI Studies Repository

1997

\title{
Harry F. Harlow and Animal Research: Reflection on the Ethical Paradox
}

John P. Gluck

University of New Mexico

Follow this and additional works at: https://www.wellbeingintlstudiesrepository.org/acwp_arte

Part of the Animal Experimentation and Research Commons, Animal Studies Commons, and the Bioethics and Medical Ethics Commons

\section{Recommended Citation}

Gluck, J. P. (1997). Harry F. Harlow and animal research: reflection on the ethical paradox. Ethics \& behavior, 7(2), 149-161.

This material is brought to you for free and open access by WellBeing International. It has been accepted for inclusion by an authorized administrator of the WBI Studies Repository. For more information, please contact wbisr-info@wellbeingintl.org.

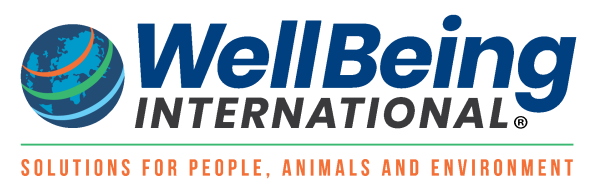




\title{
Harry F. Harlow and Animal Research: Reflection on the Ethical Paradox
}

John P. Gluck

University of New Mexico

\section{$\underline{\text { KEYWORDS }}$}

Harry F. Harlow, animal research, ethics

\begin{abstract}
With respect to the ethical debate about the treatment of animals in biomedical and behavioral research, Harry F. Harlow represents a paradox. On the one hand, his work on monkey cognition and social development fostered a view of the animals as having rich subjective lives filled with intention and emotion. On the other, he has been criticized for the conduct of research that seemed to ignore the ethical implications of his own discoveries. The basis of this contradiction is discussed and propositions for current research practice are presented.
\end{abstract}

It is a rare event when the work of a scientist stimulates students and colleagues to think reflectively and creatively about research questions. For a mentor to sustain this type of influence throughout the professional lifetime of students and coworkers and on to the next generation of researchers is truly unusual. Such is the measure, claimed by many, for the psychologist Harry F. Harlow. There is a strong basis for such an assertion.

The corpus of Harlow's work on monkey cognition and social development has been chronicled extensively in journals and the popular press. During his lifetime, Harlow published approximately 325 articles and books and received virtually every available prize for scientific achievement, including the coveted Gold Medal from the American Psychological Association, in 1973, and membership in the American Philosophical Society. In 1951, he was the first psychologist to be elected a member of the National Academy of Sciences. He received the National Medal of Science from Lyndon Johnson in 1967, the Kittay Award from the Psychiatric profession in 1975, and honorable mention from the Nobel Committee in 1973. These achievements derived from Harlow's study of the effects of drastically disturbing typical patterns of behavioral development by raising infant monkeys on cloth and wire 
surrogate mothers and in social isolation chambers that altered access to conspecifics; by insulting the integrity of the functioning nervous system with surgically inflicted or radiation-caused brain lesions; and by attempting to induce and subsequently cure human psychopathologies, known to involve significant suffering in human patients, in rhesus monkeys.

A measure of Harlow's continued importance recently was illustrated at a symposium held in his honor at the 1996 meeting of the American Society of Primatologists. At that symposium, conducted 15 years after his death, a group of prominent scientists, some of them Harlow's former students, not only celebrated Harlow's history of achievement but emphatically credited Harlow with having provided the seminal base for the current studies of behavioral development and attachment, the neurobiology of cognition, the assessment of animal intelligence, the promotion of proper animal husbandry techniques, the treatment of psychopathology in humans and nonhuman primates, and the general fostering of the cognitive revolution in the 1960s, which moved psychology away from the domination of behavioristic explanation.

Harlow also has been a flashpoint of controversy in the ethical debate over the use of animals in biomedical and behavioral research. In his precedent-setting book, Animal Liberation, Singer (1975) explicitly named Harlow's work on social isolation as a classic case example of exploitive, painful, and unjustified research. Harraway (1989) felt that Harlow's work, rather than deserving glory, justified his classification as a sadist. And Midgley (1981), a philosopher with a moderate position on animal protection, agreed that much of the work was, at the very least, ethically thoughtless. Stephens (1986) documented the variety of maternal deprivation experiments and concluded that the work was exorbitantly expensive, both financially and in animal suffering, and proved little that was not patently obvious. Even contemporaneous critics condemned the cruelty of Harlow's experiments and claimed they degraded the humanness of those who designed and executed them (Roberts, 1967).

In addition, criticism of Harlow's work recently has come from some unexpected sources. In the book The Monkey Wars, based on a Pulitzer prize-winning series of articles, Blum (1994) investigated in detail the conflicts associated with biomedical and behavioral research with nonhuman primates. She interviewed a number of influential researchers, some of whom had formal relationships with Harlow, either working directly with him at some point in their careers or working in related research areas. Although those interviewed agreed that Harlow was an exceptionally gifted intellect and that his early work was superb, several questioned his experimental judgment, especially during the later part of his career, the 1970s, when Harlow was involved in creating models of psychopathology, such as depression. For example, the protocols of some of these studies called for infant monkeys to be housed in deep, wedge-shaped, stainless steel chambers (graphically called "the pits of despair") sometimes for months at a time (Suomi \& Harlow, 1969, p. 248). These interventions devastated the animals. The published descriptions of monkeys attempting to adjust to these conditions are indeed heart wrenching. Gene Sackett, a former postdoctoral student and long-term distinguished colleague of Harlow's, was quoted by Blum as suggesting that these types of experiments, and the graphic language that was used to describe them, provided much of the tinder for the ignition of the animal protection movement. William Mason, another of Harlow's postdoctoral students, and a brilliant researcher in his own right, stated,

He kept this going to the point where it was clear to many people that the work was really violating ordinary sensibilities, and that anybody with respect for life or people would find this offensive. It is as if he sat down and said that I'm only going to be around another ten years. What l'd like to do, is leave a great big mess behind. If that was his aim, he did a perfect job. (Blum, 1994, p. 96)

So here we have these differing pictures of Harlow: Harlow as ethically thoughtless, as an animal husbandry advocate, as a creative innovator searching for the resolution of serious human problems, as 
self-absorbed, as generous, and as a sadistic experimentalist; a man credited with broadening our appreciation of the similarity of nonhuman and human primates with respect to their brain organization, learning, emotional life, and ability to suffer psychopathology, on one hand; on the other hand, a man accused of conducting cruel, inhumane, and unjustifiable research.

There is a tendency for the proponents of these different views to assert that their view is the correct one and that other views are delusion. This standoff is a net loss. The ethical debate on the use of animals in biomedical and behavioral research is too important to retreat into polemics (Gluck \& Kubacki, 1991). The issues are more important than maintaining a unidimensional view of one man, either perfectionistic or condemning. And there are points of agreement. Many of Harlow's scientific achievements were quite notable and are not particularly controversial. Nonetheless, the sources of criticism are strong. This is not the time blindly to support bad decisions that we may have made as scientists, nor is it the time to tum our backs on work done with consideration and pride. An analysis of a scientist of the stature of Harlow provides an opportunity to improve the scientific and ethical standards of our work. We must acknowledge what was valuable in his work as well as what was missing. And perhaps most important, we must identify what made Harlow insensitive to the paradox he helped to reveal.

Accordingly, I hold that another mark of exceptional greatness is the ability of a scientist to stimulate reflection beyond the specific disciplinary or topic content and into the ethical domains of their work. The history of Harlow's achievements and the criticism he stimulated offers this unusual opportunity.

The experiential perspective that I bring to this discussion is as one of Harlow's "shared" graduate students during the late 1960s and early 1970s. I was shared in that Harlow provided both broad professional mentorship and financial support, and his colleague John Davenport provided essential and specific guidance around my particular research interests, which focused on paradigms with which Harlow was relatively unfamiliar. Harlow and I collaborated directly on studying the effects of early deprivation and enrichment on later learning ability in rhesus monkeys. I found him to be generous with his time, support, advice, publication credit, and, on my graduation, with his equipment and research subjects. To this day I consider the staff and faculty that remain from my student days at the Harlow Primate Laboratory to be among the most important people in my life. I am not a completely objective outside observer.

In the sections that follow I provide a brief biographical description of Harlow ${ }^{1}$, a general overview of his scientific contributions, and a discussion of factors believed to have contributed to his lack of ethical responsivity. These factors are divided into general background factor, personal stylistic strategies, and laboratory organization. Many of these later factors are derived from my own experience and observations.

\section{FAMILY AND EDUCATIONAL BACKGROUND}

Harlow was born Harry Frederick Israel in 1905, the second youngest of four brothers, in the small town of Fairfield, lowa. Harlow described his mother as an energetic woman, and his father as somewhat of a ne'er-do-well who left medical school, owned a marginally successful grocery store, and "foolishly" turned down the opportunity to purchase the rights to a Ford Motor Company dealership when such dealerships were still a bargain. Early in his life, Harlow's mother became occupied with the care of his youngest brother, who suffered from Potts disease. Harlow indicated that he believed this loss in maternal attention was in part responsible for a lifelong ambivalence toward women. Indeed, bitter-sounding, sarcastic remarks directed at women were to become a source of embarrassment and criticism later in his life. In interviews, Scott Jordon, a prominent Fairfield attorney who was acquainted with the family, described them as a quite closed group who kept primarily to themselves. The brothers were described as having 
few peer relationships, preferring to interact among themselves. Harlow described himself as a callow youth, so shy that he would apologize to doors before opening them. The anguish of serious mental illness was a significant part of Harlow's family experience; his brother Delmer suffered from severe depression, and Hugh may have experienced schizophrenia. Harlow also was to be tormented by depression during his adult life, eventually requiring hospitalization at the Mayo Clinic in 1967.

The family expressed high educational expectations, in part by showing a willingness to spend their resources on education. Harlow and his two older brothers attended the elite Reed College in Portland, Oregon, and he eventually transferred to Stanford University, where he completed his formal education.

During his doctoral training at Stanford, Harlow worked with two mentors: the comparative psychologist Calvin P. Stone and the developmentalist and IQ researcher Lewis Terman. At the time of graduation there was concern that a significant speech impediment and a Jewish-sounding last name (Harlow was not Jewish) would interfere with his finding an appropriate academic position. Therefore, Terman suggested that he change his name. He adopted the name Harlow, and soon he was offered a position at the University of Wisconsin. Although he could change his last name quickly, his speech impediment and extreme shyness remained. According to his first wife, Clara Mears, who was a graduate student in the department of psychology at the time of his hiring, the impediment and shyness brought overt ridicule from students in the form of boos and catcalls. In classes he frequently felt humiliated and disgraced. However, he managed to overcome the impediment and became one of the most sought-after speakers in the field of psychology (Suomi \& LeRoy, 1982).

Harlow married Clara Mears in 1932. They had two sons, Robert and Richard, during 14 years of "intermittent happiness." They were divorced in 1946. Shortly after the divorce, Harlow met Margaret Kuenne, a new assistant professor in the Department of Psychology. They were married in 1948. Once this fact was discovered, antinepotism rules forced Margaret Kuenne to leave the Department of Psychology, and she moved to the Department of Educational Psychology. During their marriage they had two children, Pamela and John. After Margaret's death, Harlow remarried Clara Mears in 1972, retired from the University of Wisconsin in 1974, and moved to the University of Arizona in Tucson, where he lived until his death in 1981.

This brief overview depicts a man raised in a home of modest financial means and high educational and professional expectations, a man with direct experience concerning the impact of serious psychopathology and a strong need to overcome social and communicative barriers.

\section{GENERAL HISTORICAL BACKGROUND}

Harlow was an early soldier in psychology's campaign to be acknowledged as a natural science. This acknowledgment was judged to require the employment of scientific methodology, which widely was interpreted to mean the explicit use of experiment and controlled observation (see Boring, 1952).

According to the much-told story (Suomi \& LeRoy, 1982), on his arrival at the Wisconsin campus, Harlow was told by the department chair that the animal facilities recently had been destroyed in a fire. He was encouraged to continue his animal behavior work studying the primates housed at Madison's Vilas Park Zoo. Soon after this suggestion, Harlow initiated a research program concerned with the learning abilities of nonhuman primates at the university proper. In this program he adapted for animal use some of the evaluation techniques of the human intelligence testing movement to which he had been exposed by Terman at Stanford. This move created a unique experimental niche for the young psychologist and placed him firmly in the experimental zeitgeist. 


\section{Monkey Cognition}

Harlow's work on the process by which monkeys learn to solve discrimination problems began to attract attention. He proposed that monkeys solved discrimination problems by developing various "hypotheses" about the solution. According to this view, the process of learning proceeded as incorrect hypotheses steadily were eliminated in favor of the correct approach. These hypotheses could then be applied to similar problems encountered in the future. In his words, the monkeys "learned how to learn" (Harlow, 1949, p. 53). This proposal explicitly rejected mechanistic explanations of animal learning then favored by behaviorists. The behaviorist perspective explained the changes seen during learning as the result of the connection or disconnection of small response units to specific stimuli through the action of contiguity, reward, nonreward, and punishment. In addition, the whole process of learning was thought to be motivated by the need to reduce internal biological drives like hunger and thirst (see Spence, 1952). Instead, Harlow described monkeys as having complex cognitive abilities that involved the existence of intentions, curiosity, and solution plans. This was not a description of insensate automata implied by some behavioristic explanations.

As the program progressed, Harlow found it would be necessary to raise monkeys in the laboratory. This capability would allow him to specify and control the life histories of the animals, study the development of learning abilities from birth to adulthood, and control tuberculosis outbreaks among the animals caused by infected monkeys trapped in the wild and brought to the laboratory. Therefore, procedures were developed (Blomquist \& Harlow, 1961) by which infant monkeys were separated from their mothers at birth and raised in a nursery by technicians.

\section{Raising Monkeys Without Mothers as an Investigative Procedure}

By the mid-1950s Harlow began to use the motherless rearing protocol as a way to study the factors that contributed to the attachment bond between a mother and infant. Human and nonhuman primate offspring alike maintain proximity to the mother and seek out her protection at times of stress and danger. But what accounted for the connection? Pursuit of an answer to this and related questions was a turning point in Harlow's research career.

In the 1950s the favored explanation of the development of the early attachment bond between human mothers and their infants was the theory of secondary drive. According to this perspective, the infant becomes attached to the mother because the mother's feeding actions meet the infant's pressing physiological needs. In time, the infant comes to recognize that she is the source of the experienced gratification and becomes attached. In other words, attachment is conditioned or "derived" from feeding. On the other hand, members of the psychoanalytic tradition called the British Middle Group believed in the innate importance of contact and clinging in the development of attachment (Bowlby, 1953). They rejected the idea that attachment was a secondary process. As clinicians, they argued the point from the perspective of theory, clinical experience, and intuition. It was at this point that Harlow entered the fray, bringing the point of view of an experimentalist: "Our assigned mission as psychologists is to analyze all facets of human and animal behavior into their component variables. So far as love or affection is concerned, psychologists have failed in this mission" (Harlow, 1958, p. 673).

Testing these differing conceptualizations in the format of a traditional experiment would require an approach that could determine the effect of feeding independently from other factors. Eventually an experiment was designed in which infant monkeys separated from their mothers at birth were given a choice between a wire mother surrogate that provided nutrition and a soft-bodied surrogate who provided no nutrition. Results demonstrated that the monkeys overwhelmingly preferred to maintain physical contact with the soft mothers. It also was shown that the monkeys seemed to derive a form of emotional 
security by the very presence of the soft surrogate that lasted for years, and they "screamed their distress" in "abject terror" (Harlow \& Zimmerman, 1959, p. 423) when the surrogate mothers were removed from them. Once again Harlow described monkeys as experiencing feelings that included joy, fear, anxiety, and depression.

For the next 20 years Harlow proceeded to dissect the nature of social bonds in animals by studying the effects of occluding and rearranging the "normal" course of development. He did this with the same directness he had employed when studying the neurobiology of learning. Brain regions suspected as participating in abstract learning were destroyed by lesion or removed by surgical extirpation. The effects of the modified brain were then observed (e.g., Harlow, 1955). He adapted the same strategy to studies of social development; but instead of removing or disrupting brain parts, he removed or disrupted mothers, peers, and social experience. Here, instead of the animal pain being something that needed to be avoided, the analysis or production of emotional distress and dysfunctional behavior was often the object of the experiments. Many of these experiments produced animals with what eventually was referred to as the isolate syndrome. This syndrome is characterized by animals who avoid social contact and show high amounts of fear, self-clutching, body rocking, and sometimes even self-injurious behavior.

\section{THE DILEMMA}

The stated premise of Harlow's work was that rhesus monkeys possessed many subjective psychological states that were analogous to human states. More specifically, monkey anxiety, distress, affection, and depression were believed to model human conditions in a substantive way. Because producing such states in humans could lead to serious harm, ethical considerations prevented their manipulation. If the psychological states are analogous, the dilemma posed concerns the right by which we are allowed to discount the moral significance of the noxious states and proceed to induce them in animals. If the psychological states are not analogous, what is the point of inducing them (Rollin, 1989)? Given Harlow's position, he would need to show why monkeys were excluded from the moral consideration required for humans. Among Harlow's colleagues, William Mason recognized these issues and published a number of articles in which he attempted to work through the conflict between a scientist's wish to understand the natural world and the "rights" of inherently valued animals to a life of noninterference (e.g., Mason, 1990).

Although Harlow described animals as having complex subjective lives, it seems quite clear that he maintained an unsentimental attitude toward them. Keeping in mind that he had a penchant for overstating things for dramatic purposes, Harlow commented to an interviewer in 1974:

The only thing I care about is whether the monkeys will turn out a property I can publish. I don't have any love for them. Never have. I really don't like animals. I despise cats, I hate dogs. How could you like a monkey? (as quoted in Blum, 1994, p. 92)

Harlow (1960) also took pride in the fact that the nursery procedures he helped develop led to animals freer of disease than were those produced by "real" monkey mothers. In other words, Harlow saw animals as experimental resources and tools, an attitude not too unusual among researchers of his time. Although he certainly was aware of the animal protection legislation in place in the United Kingdom since 1876, active legislative attempts in the United States did not begin until 1960 (the Laboratory Animal Welfare Act was passed in 1966). Therefore, I think it is fair to conclude that Harlow was neither cognizant of nor responsive to the dilemma that faced him. What factors can be identified that help explain this lack of consideration? 


\section{Factors That Limited Ethical Analysis}

We have identified Harlow as a thoroughgoing experimentalist with an unsentimental view of animals. If animals had value it was derived from the benefits their use produced. He also openly acknowledged that he was motivated strongly by achievement and public prestige. Although in themselves these attributes are not necessarily problematic, coupled with insulation from ethical feedback, they might lead to experimental excess. A number of factors served to provide a buffer to ethical consideration. We focus on five sources.

Prominence. By the time Harlow became involved with experiments that intentionally included the production and analysis of emotional and affective distress, he was already a renowned scientist. By the mid-1950s he already had served as president of the Division of Experimental Psychologists of the American Psychological Association, had been elected a member of the National Academy of Science, had a named chair in the department of psychology, and had been elected to the elite Society of Experimental Psychologists. By 1970 he had won the highest award for science offered by the U.S. Government. There is no question that such a record served to support assumptions of credibility and made criticism by other scientists difficult. For example, Blum reported that even Suomi, a former student, respected collaborator, staunch supporter, and friend, felt that he had to wait until Harlow retired from the University of Wisconsin before he could shut down the "pit" projects, on which he collaborated (see Suomi \& Harlow, 1969), because they had been causing him "nightmares" (Blum, 1994, p. 96).

Presentation style. During oral and written presentations Harlow used startling language to describe his experimental work. Rejecting surrogate mothers were called "iron maidens," procedures intended to expose monkeys to long-term mild punishment were called "pit and the pendulum" strategies, an apparatus constructed to prevent female monkeys from rejecting sexual partners was called the "rape rack." Monkeys exposed to socially isolating procedures were described as "crushed" and "destroyed." At the same time, he also included language that seemed intended to soften the impact of those descriptions, a type of rhetorical disguise. For example, he called his discussion of the sexual dysfunctions of socially isolated animals his "Sermon on the Mount." His speeches and writing were salted liberally with alliterations and rhymes. Poetry, science, and brutally direct descriptions were fused together. At one level the presentations could be gripping, at another level the apparent glibness and certainty, coupled with his scientific stature, deflected criticism from all but the most strident antagonists.

Feedback from colleagues. When Harlow received comments about his treatment of animals, what form did they take? Early in his career Harlow was engaged in determining whether skeletal responses could be conditioned without muscle movement. The experimental protocols called for paralyzing an animal, exposing it to some contingency (e.g., a light preceding a shock to a leg), and then testing to see if the animal showed a learned flexion of the limb when tested in the normal state. In commenting on the results of such an experiment, in an unpublished biographical manuscript, he wrote, "I can only say that the paper was originally rejected by the Journal of Experimental Psychology who thought that the pictures of our totally paralyzed monkeys were so totally reprehensible that they would give the journal unfavorable publicity" (Harlow, 1970, p. 19). Apparently the editors suggested that instead of photographs, schematic drawings of the animals should be used (see Harlow \& Stagner, 1933). This comment reveals some degree of insensitivity, but the response of the editors to this young professor was not that the work should not have been conducted or published; rather, its presentation needed to be sanitized because of potential bad publicity. Similarly, E. H. Eyestone, Chief of the Animal Resources Branch of the National Institutes of Health (NIH), wrote a letter on July 10, 1969, to Robert Bock, Dean of the College of Arts and Sciences at the University of Wisconsin, in which he expressed the concern of a review committee with the "pits of despair" experiments. Any concerns for welfare and humaneness were reduced to issues of publicity: 
The month-long confinement of monkeys in deep wedge-shaped boxes gave the review committee cause for concern. In view of Federal regulations designating minimal size of cages, it was believed that these wedge-shaped cages are illegal and inhumane. Their use could make the Center vulnerable to unfavorable publicity. (p. 7)

With the exception of the comments of William Mason, the criticisms of Harlow's work by his colleagues collected by Blum (1994), and mentioned earlier, refer almost exclusively to the negative impact on the public of his untamed language. In other words, there was more discussion about the expression of the reports than with the experiments themselves. In fact, such prominent researchers as Levine, Suomi, and Sackett continue to be involved with many of the same types of experiments for which Harlow was criticized.

Support of John Bowlby. The relationship between Harlow and the eminent British psychiatrist John Bowlby is a factor of central importance. By the conclusion of World War II Bowlby was established as an internationally respected child clinician and attachment theorist. As a leader of the British Middle Group he was opposed vehemently to the conceptualization of attachment as a secondary process. For Bowlby the stakes ran deeper than a mere theoretical debate about the importance of the feeding experience. Instead, he believed that this way of conceptualizing attachment dangerously minimized the actual pathological power of failed attachment. He held that good mental health essentially was dependent on the child's establishing and learning to maintain proper attachment relationships. In Bowlby's view, the discovery of this concept "may be compared to that of the role of vitamins in physical health" (Bowlby, 1953, p. 69). Therefore, interpreting the attachment process as "derived" had helped maintain a blindness to this fundamental principle. He felt that this blindness had disastrous consequences for the promotion of proper childrearing practices and the treatment of mentally ill children.

In early 1957 Bowlby was made aware of Harlow's plan to study attachment in monkeys. In August of that year Bowlby sent Harlow a draft copy of "The Nature of the Child's Tie to the Mother" and asked for his comments. The following October Harlow responded to Bowlby that the article was, in essence, a blueprint for his own research, and Harlow invited Bowlby to visit his laboratory. Bowlby visited the primate laboratory in June 1958, several months before Harlow's presidential address to the American Psychological Association in which he presented the results of the mother surrogate experiments. From that point on Bowlby and Harlow maintained a relationship of mutual respect and support. In fact, Bowlby (1969) credited Harlow with providing much needed experimental evidence for his clinically derived beliefs. There is little question that such advocacy served to inhibit questions of experimental relevancy that might emerge.

Laboratory organization. The last 20 years of Harlow's experimental career were characterized by financial security. The plentiful grant support led to an organizational structure characterized by an expert division of labor. The laboratory professional staff came to include highly trained animal care technicians, veterinarians, experienced monkey testers, statisticians, and editorial consultants. Although this division led to efficiency and productivity, it also had the effect of reducing the need for any one person to be involved directly with the entire experimental process. In other words, it was possible for investigators to visualize an experiment, get authorization for the use of the animals, have the animals exposed to the relevant variables, have the data collected and analyzed, and have the results presented to them without significant direct exposure to the consequences on the animals of the entire process. In the later years Harlow had little direct contact with the subjects of his experimental designs. In this situation the reality of the plight of the experimental animals could be obscured by the abstract goals of the experiment. And this could result in a further limitation of input that might stimulate ethical reflection. 


\section{CONCLUSIONS}

A review of the Harlow case leads to a chilling recognition. That is, in many respects the factors identified as impediments to ethical reflection are, at the same time, indicators of academic excellence and deserved confidence. An efficient and productive laboratory is headed by a prominent and "hard-nosed" scientist with excellent communication skills, a scientist who receives strong support from prominent clinicians concerned with research applications. However, the existence of an unspoken and unanalyzed ethical theory by which animals were ruled out of consideration deprived Harlow of the needed sense of hesitancy. In other words, the use of animals in research must be rooted in a strong sense of ethical selfexamination. Ethical self-examination involves a careful examination of one's personal and scientific motives. Moreover, it requires a recognition of the reality of animal suffering that accompanies some research. This suffering must be considered in the context of one's ethical values (Gluck \& Kubacki, 1991). The case of Harry F. Harlow provides us with indications concerning how one can become insulated from the need for such an analysis.

A number of suggestions emerge from the consideration of Harlow's work.

1. A researcher must explicitly invite ethical comment. A position of prominence and power is most likely to mute any such inclinations, even among senior colleagues. The invitation must be extended particularly in the face of strong interest and advocacy. We must do more than just claim the moral high ground of essential research, we must be able ethically to justify the claim.

2. Whereas a concern for bad publicity may alert us to the existence of an ethical problem, adequate ethical consideration cannot be limited to this concern. Bad publicity does not necessarily mean the public does not understand, is incapable of understanding, and must be spared the unsavory details.

3. Any organizational scheme that limits scientists' actual contact with the impact of their work on the animals must be avoided. Direct observation of the conditions of the animals offer an opportunity for consideration and reflection. As Gruen (1992) put it, "The immediacy of a human situation will often cause the wall of abstraction separating us from our empathic potential to crumble" (p. 52). In summary, the rigor of our ethical analysis must match the rigor of our purely scientific considerations.

\section{REFERENCES}

Blomquist, A. J., \& Harlow, H. F. (1961). The infant rhesus monkey program at the University of Wisconsin Primate Laboratory. In Proceedings of the Animal Care Panel, 57-64.

Blum, D. (1994). The mankey wars. New York Oxford University Press.

Boring, E. G. (1952). The validation of scientific belief. Proceedings of the American Philosophical Society, 96, 535-539.

Bowlby, J. (1953). Child care and the growth of love. Harrnondsworth, England: Penguin.

Bowlby, J. (1969). Attachment and loss. New York: Basic Books.

Gluck, J. P., \& Kubacki, S. (1991). Animals in biomedical research: The undermining effect of the rhetoric of the besieged. Ethics and Behavior, I, 157-173.

Gruen, A. (1992). The insanity of normality. New York: Grove Weidenfeld.

Harlow, H. F. (1949). The formation oflearning sets. Psychological Review, 56, 51-65.

Harlow, H. F. (1955). The brain and learned behavior. Computers and Automation, 4, 6-14.

Harlow, H. F., \& Zimmerman, R. R. (1959). Affectional responses in the infant monkey. Science, 130, 421-432.

Harlow, H. F. (1960). Oflove in infants. Natural History, 69, 18-23.

Harlow, H. F. (1970). Autobiography. Unpublished manuscript. 
Harlow, H. F., Harlow, M. K., \& Suomi, S. J. (1971). From thought to therapy: Lessons from a primate laboratory. American Scientist, 59, 538-549.

Harlow, H. F., \& Stagner, R. (1933). The effect of complete striate muscle paralysis upon the learning process. Journal of Experimental Psychology, 16, 283-294.

Harraway, D. (1989). Primate visions: Gender, race, and nature in the world of modem science. New York: Routledge.

Mason, W. A. (1990). Premises, promises, and problems of primatology. American Journal of Primatology, 22, 123-138.

Midgley, M. (1981). Why knowledge rnatters.In D. Sperlinger (Ed.), Animals in research (pp. 319-336). New York: Routledge.

Roberts, C. (1967). The scientific conscience: Reflections on the modern biologist and humanism. New York: Braziller.

Rollin, B. E. (1989). The unheeded cry: Animal consciousness, animal pain and science. New York: Oxford University Press.

Singer, P. (1975). Animal liberation: A new ethic for our treatment of animals. New York: Avon.

Spence, K. W. (1952). Cognitive versus stimulus-response theories of learning. Psychological Review, $57,159-172$.

Stephens, M. (1986). Maternal deprivation experiments in psychology: A critique of animal models. Jenkingtown, PA: American Antivivisection Society.

Suomi, S. J., \& Harlow, H. F. (1969). Apparatus conceptualization for psychopathological research in monkeys. Behavior Research Methods and 1nstrumentation, 1, 247-250.

Suomi, S. J., \& LeRoy, H. A. (1982). In memoriam: Harry F. Harlow (1905-1981). American Journal of Primatology, 2, 319-342.

\section{Notes}

${ }^{1}$ Much of the material presented in this section was provided during discussions with Helen LeRoy, who for many years was Harlow's editorial and personal associate. The statements are based on oral history and archival documents both extensively studied and held in trust by her. 